\title{
The contribution of Sentinel-2 satellite images for geological mapping in the south of Tafilalet basin (Eastern Anti-Atlas, Morocco)
}

\author{
Said FAL ${ }^{1}$, Mehdi MAANAN ${ }^{1}$, Lahssen BAIDDER ${ }^{1}$, Hassan Rhinane ${ }^{1}$ \\ (1): geosciences laboratory, Faculty of sciences Hassan2 University B.P 5366 Maarif Casablanca 20100 Maroc (saidgeo, \\ mehdi.maanan, lbaidder, h.rhinane)@gmail.com
}

Keywords: Sentinel-2 - Tafilalet - Anti-Atlas - OIF - MNF - MLC - SAM

\begin{abstract}
:
Geological mapping in desert, mountainous or densely vegetated areas are sometimes faced with many constraints. Recently several remote sensing methods are used on ASTER or LANDSAT imagery for making that task easier. The aim of this paper is to evaluate the applicability of some of these methods on Sentinel-2A images. The study, therefore, focuses on a lithological classification using these multispectral images in the south of the Tafilalet basin. To achieve this goal, two L1C level images were used. Decorelation stretch combined with the optimal index factor (OIF) and Minimum Noise Fraction (MNF) were the main improvements used for RGB combination images. The classifiers Spectral Angle Mapper (SAM) and the Maximum Likelihood classifier (MLC) have been evaluated for a most accurate classification to be used for our lithofacies mapping. The latest drawn geological maps and RGB images of false colour combinations were used to select regions of interest (ROI) as the endmembers to use for these classifiers. Obtained results showed a clear discrimination of the different lithological units of the study area. Classifications evaluation showed that the Maximum likelihood classifier is more accurate with an overall accuracy of $76 \%$ and a Kappa coefficient is 0.74 . Finally, this study has shown the importance of the use of sentinel-2 multispectral images in geological mapping and has shown that the high spectral resolution of the VNIR and SWIR bands creates a synergy with the high spatial resolution for optimal lithological mapping.
\end{abstract}

\footnotetext{
* Corresponding author
}

\section{INTRODUCTION}

The field geological studies have always been very important for any resource exploration (mineral, hydro-geological, Petroleum industry or civil engineering domains). The good basic geological mapping is an absolute necessity for having an optimal exploitation of these resources. The geological investigations in desert areas, densely vegetated or areas with difficult access, has always been a very hard task. Sometimes, improper extrapolation of the interpretation of geological features in the field, like structures and lithological boundaries, produces inaccurate geological maps.

Since the seventies (Bishop et al., 2018a), satellite imagery, with various missions and instruments, has allowed geological mapping to take a big step forward with the use of remotely sensed data. Geological remote sensing that debuted recently(Gregory, 1979)with the use of low resolution images of landsat1; has evolved in parallel with the progression of the satellite programs that followed; like Landsat2 to Landsat8; ASTER and others Multi or hyperspectral satellites, for more details see (("Satellite Missions Directory - Earth Observation Missions - eoPortal," n.d.).

Over the past three decades, the use of multispectral data has increasingly permitted determining the nature of minerals and rocks. Thus, the development of new methodologies by these multispectral images has made geological mapping even easier. In these images, each object has a spectral signature that is a specific response to the radiation to which it is subjected. For rocks, these spectra vary with several factors; After (Abdelmalik and Abd-Allah, 2017); rock type, thickness, geometry, isotropism, metamorphism and weathering are the main factors controlling the reflection behaviour of these rocks. Thus, to highlight the spectral characteristics of each rock, several studies (Adiri et al., 2017; Amri et al., 2017;
Asadzadeh and de Souza Filho, 2016; BinamMandeng et al., 2018; Kumar et al., 2015; Ninomiya and Fu, 2016; Pour and Hashim, 2012; Rajendranand Nasir, 2017) have used many enhancement treatments on Landsat and/or Aster images. Many authors reviewed various methods and various spectral processing for geological mapping e.g. (Asadzadeh and de Souza Filho, 2016; Bishop et al., 2018b; van der Meer et al., 2012)multiple reviews were about enhancements used for SWIR and VNIR bands of ASTER and/or Landsat images. Recently launched, Sentinel-2 with its Multi-Spectral instrument has shown its effectiveness in several studies on different subjects. In literature, they include salinity discrimination (Bannari et al., 2018), vegetation studies(Frampton et al., 2013; Qiu et al., 2017), water bodies mapping (Kaplan and Avdan, 2017), lake water quality (Toming et al., 2016) and coral reef mapping(Hedley et al., 2016)

The use of MSI Sentinel-2A for geological remote sensing was first evaluated by (van der Meer et al., 2014). He compared the capacity of the Sentinel 2A MSI bands to that of ASTER and Landsat 8 VNIR and SWIR bands. He concluded that these bands can be used in band ratios that were previously designed for ASTER and Landsat. He has also demonstrated a good correspondence between those bands.

In the present paper; based on the geological studies carried in the region of Tafilalet (Baidder et al., 2016, 2008; Lubeseder et al., 2010; Michard et al., 2008; Soulaimani and Burkhard, 2008) and based on the remote sensing methods used in such geological mapping studies (Bishop et al., 2018b; Fagbohun et al., 2017; Rajendran and Nasir, 2017; Asadzadeh and de Souza Filho, 2016; van der Meer et al., 2012; Bannari et al., 2015, 2016); we try to deduce the best improvement procedure (OIF, DS or MNF) that can be used to discriminate rock lithology encountered in the region. We also aim to classify lithofacies by processing sentinel $2 \mathrm{~A}$ multispectral data. For this purpose, the angle spectral mapper (SAM) and the maximum likelihood 
classifier (MLC) were used for classification. The regions of interest (ROI) spectra of the image were used as endmembers. For best accuracy; SAM and MLC classifiers were compared and a choice was made for the classifier to be used as a support for geological mapping. The validation was done using localized truth ROIs with the GPS coordinates of outcrops in the field (collected samples) and on the geological map at $1 / 50000$.

\section{MATERIALS AND METHODS}

\subsection{Study site and geological settings.}

The study area (fig. 1 ) is located near to the eastern boundary of Morocco between the coordinates $4^{\circ} 30^{\prime} \mathrm{W} 31^{\circ} 15^{\prime} \mathrm{N}$ and $3^{\circ} 45^{\prime} \mathrm{W} 30^{\circ} 45^{\prime} \mathrm{N}$. It's known forits semi-arid to arid climate and its outstanding geological landscapes, outcrops and fossils. Structurally; it's located in the southern part of the OUGNAT-OUZINA axis and in the southeast of the Tafilalet basin. It is limited at the east by the Guir Hamada, and at the west by the MAIDER basin. It is bounded by the KemKem domain and the Oumjrane-Taouz fault (OJTF) at the south and at the North by the Erfoud anticlinorium. The area is recognized by its highly mixed lithology and surprising structures such as the croissant or boomerang-shaped Tijekht anticline(Baidder et al., 2016).

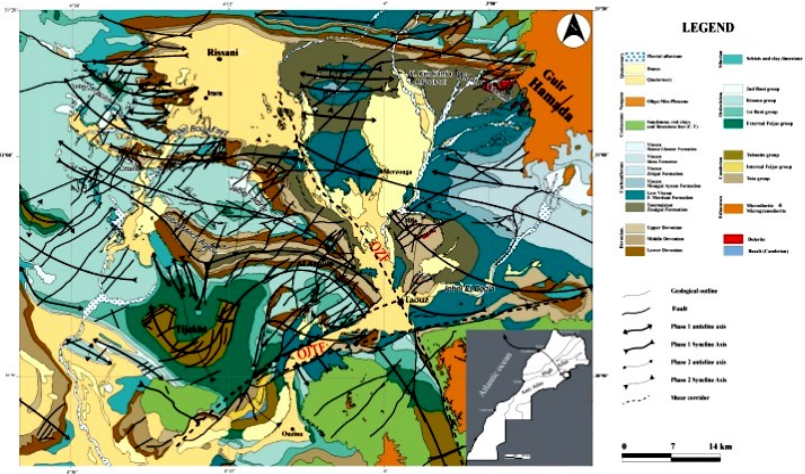

Fig.1. lithological outcrops and Structural schema of the study area (South Ougnat-Ouzina axis and Southeast Tafilalet Basin), modified after (ALVARO et al., 2014b;

BENHARREF et al., 2014b) and assembled from Irara and

Merzouga sheets of the geological map of Morocco at

1/50000 (National Plan for Geological Mapping). OJTF: Oumjerane-Taouz Fault; OZF: OuedZiz Fault.

After previous studies in the region (ALVARO et al., 2014b; Baidder et al., 2016, 2008; BENHARREF et al., 2014b; Lubeseder et al., 2010; Michard et al., 2008; Pouclet et al., 2017; Soulaimani and Burkhard, 2008), lithological outcrops encountered range from Precambrian to Quaternary. The formations are folded along east-west axes withbending axes to the east. The anticlines expose the Cambrian and Ordovician, while the synclines include the Devonian andtheCarboniferous. Those formations are mainly sedimentary to weakly metamorphised. They are hosting (Pouclet et al., 2017) some magmatic alkaline rocks such as doleritic or basaltic sills or laccoliths.

According to the explanatory notes of recent sheets at $1 / 50000^{\circ}$ of Moroccan geological map "sheets of: Al Atrous, Irara, Merzouga, Mfis and Tawz" (ALVARO et al., 2014a, 2014b; BENHARREF et al., 2014c, 2014a, 2014b) the formations encountered in the study area are summarized, in the figure 4 .

\subsection{Data sets used}

The data used in our study is composed of Sentinel-2A images and geological map of Morocco at $1 / 50000^{\circ}$ (sheets mentioned above). SENTINEL-2A is a wideswath $(290 \mathrm{~km})$, highresolution, multi-spectral imaging mission. Its instrument (MSI) samples 13 spectral bands: (i) four VNIR bands (B2, $\mathrm{B} 3, \mathrm{~B} 4$ and $\mathrm{B} 8)$ at $10 \mathrm{~m}$, (ii) four red edges bands(B5, B6, B7 and B8a) andtwo SWIR bands (B11 and B12) at 20m, (iii) three bands (aerosol, water vapour and cirrus SWIR respectively $\mathrm{B} 1, \mathrm{~B} 9$ and $\mathrm{B} 10$ ) at $60 \mathrm{~m}$ spatial resolution (Table $1)$.

\begin{tabular}{|c|c|c|c|c|}
\hline & $\begin{array}{c}\text { S2 } \\
\text { band }\end{array}$ & $\begin{array}{c}\text { Spatial } \\
\text { Resolution } \\
(\mathrm{m})\end{array}$ & $\begin{array}{c}\text { Central } \\
\text { Wavelength } \\
\text { (nm) }\end{array}$ & $\begin{array}{l}\text { Bandwidth } \\
\text { (nm) }\end{array}$ \\
\hline \multirow{10}{*}{ 妾 } & 1 & 60 & 443 & 20 \\
\hline & 2 & 10 & 490 & 65 \\
\hline & 3 & 10 & 560 & 35 \\
\hline & 4 & 10 & 665 & 30 \\
\hline & 5 & 20 & 705 & 15 \\
\hline & 6 & 20 & 740 & 15 \\
\hline & 7 & 20 & 783 & 20 \\
\hline & 8 & 10 & 842 & 115 \\
\hline & $8 \mathrm{a}$ & 20 & 865 & 20 \\
\hline & 9 & 60 & 945 & 20 \\
\hline \multirow{3}{*}{ 点 } & 10 & 60 & 1375 & 30 \\
\hline & 11 & 20 & 1610 & 90 \\
\hline & 12 & 20 & 2190 & 180 \\
\hline
\end{tabular}

Table1. .Spatial and spectral characteristics of sentinel 2A bands (https://sentinel.esa.int)

Two granules at level-1C, with Top of Atmosphere (TOA) reflectance were acquired from the Copernicus Open Access Hub Https://scihub.copernicus.eu/dhus/\#/home.

S2A_MSIL1C_N0205_R051_T30RUV_20170913T105335 S2A_MSIL1C N0205_R051_T30RVV_20170913T105335. They overlap the study area and are projected with UTM at the $30 \mathrm{~N}$ zone. They were chosen with $0 \%$ cloud coverage and were sensed on the same time: 2017-09-13T10:50:21

\subsection{Methodology}

The flowchart of the methodology used in this study is shown in Figure 2 and the processes are described below. The software used is: (i) Sentinel Application Platform SNAP 5.0 for atmospheric correction and resizing; (ii) ILWIS OPEN 3.8.5.0 for the calculation of the OIF; (iii) "Image Viewing Environment" (ENVI) 5.3 for all other pre-processing and processing and (iv) "Arc Geographic Information System" (ArcGIS) 10.3 for layout.

2.3.1. Pre-processing: The two TOA (Top of Atmosphere) sentinel granules were radiometrically and geometrically precorrected at the ESA sentinel hub. The atmospheric correction was applied by the "SEN2COR L2A" processor (SEN2COR, n.d.), implemented in the Sentinel2 SNAP Toolkit; downloaded from: http://step.esa.int/main/

A corrected image "level $2 \mathrm{~A} "$ with the reflectance at the bottom of the atmosphere (B.O.A.) has resulted for each granule. The $20 \mathrm{~m}$ resolution bands $(5,6,7,8 \mathrm{a}, 11$ and 12$)$ were resampled to $10 \mathrm{~m}$ with nearest neighbour method. Then, for each granule; all bands (2, 3, 4, 5, 6, 7, 8, 8a, 11 and 12) were stacked and the resulting images were mosaicked based on the georeference(figure3). Similarly, the sheets of the 1: $50000^{\circ}$ geological map have been mosaicked (figure4) and co- 
registered on the Sentinel-2 image resulted from the preprocessing steps.

2.3.2. Image enhancements: All of the enhancements used in the study have been applied to the mosaic resulting from the pre-processing above, but for Optimum Index Factor, the bands must be in 8 bits format.

2.3.2.1.. Optimum index factor "OIF": Chavez (Chavez et al., 1982) developed optimum index factor (OIF) to identify the combination that contains the most information and the least amount of duplication. It chooses the best band combination to use for interpretation. In the OIF method, the optimal band combination is determined according to the standard deviation of the bands and the inter-band correlation coefficient. Usually, the informative bands have small correlations and large spectral variance.

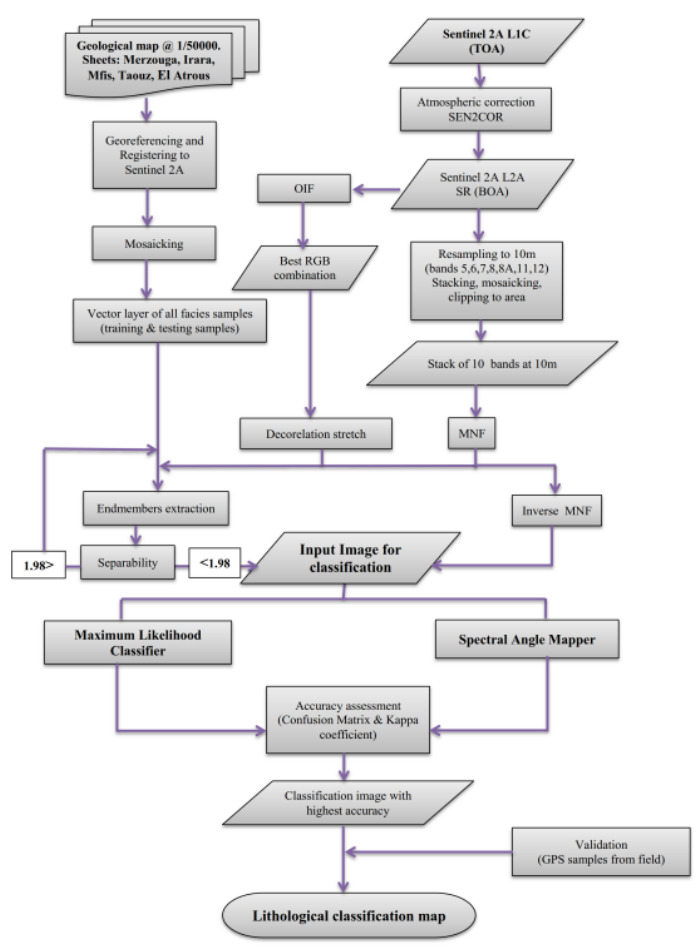

Figure 2: Flowchart of the methodology

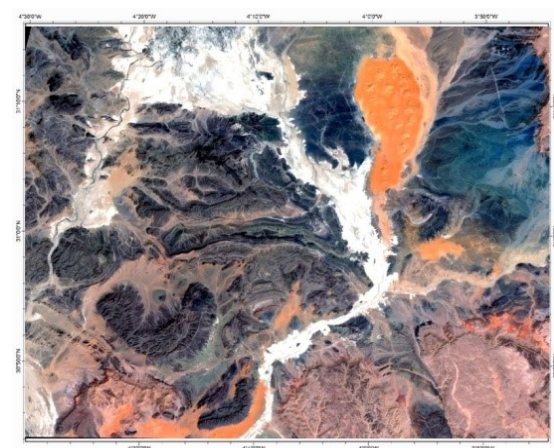

Figure3: RGB (432) true-colour mosaic image of the study area (resulted from pre-processing)

The optimum combination of bands out of all possible 3-band combinations is the one with the highest amount of 'information' (highest sum of standard deviations), with the least amount of duplication (lowest correlation among band pairs). The algorithm used for calculating the OIF is composed of three steps (ILWIS software help): (i) The number of possible combinations of three bands within the map list is determined, (ii) then, for each combination of three bands, the OIF is calculated as (1):

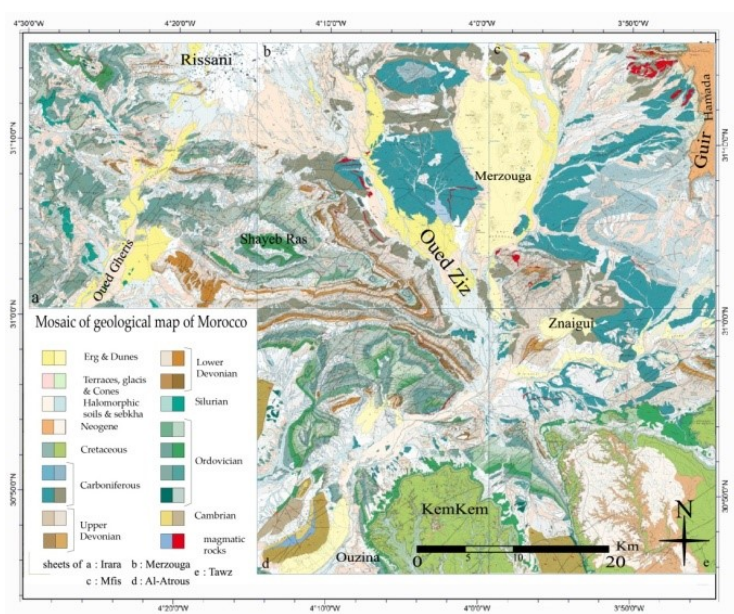

Figure4: Mosaic of geological map of Morocco at 1/50000 (sheets: a: Irara; b: Merzouga; c: Mfis; d: Al Atrous; e: Tawz) (ALVARO et al., 2014a, 2014b; BENHARREF et al., 2014c, 2014a, 2014b)

$$
O I F=\frac{\sum_{k=1}^{3} S_{k}}{\sum_{j=1}^{3} A b s\left(r_{j}\right)}
$$

Here: $\mathbf{S}_{\mathbf{k}}$ is the standard deviation for bandk, and $\mathbf{r}_{\mathbf{j}}$ is the absolute value of the correlation coefficient.

(iii) Finally, the OIF values are ranked for all RGB combinations.

The largest OIF will generally have the most information (as measured by variance) with the least amount of duplication (as measured by correlation).

2.3.2.2. Decorrelation stretch: Decorrelation Stretch is used to remove the high correlation (figure5) commonly found in multispectral data sets.

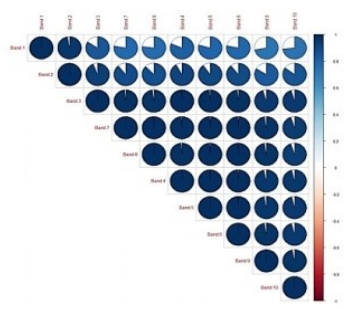

Figure 5: Correlogram of sentinel-2A bands used in the study.

(Solid ellipse and darker blue show higher correlation)

It requires three bands for input and produces a more colourful composite image with less correlation.

2.3.2.3. Minimum Noise Fraction (MNF): $M N F$ is a noise reduction process used to increase the signal-to-noise ratio (SNR) in multispectral images. It is an algorithm (GREEN et al., 1988) that consists of two consecutive rotations of PCA: (i) the first rotation use the noise covariance matrix to decorrelate and resize the noise in the image (Noise whitening process). Thus the noise has a unit variance and no band-toband correlation, (ii) the second rotation uses the principal 
components derived from the result of the first rotation. The data space is divided into two parts: one part associated with large eigenvalues and coherent Eigenimages, and a complementary part with near-unity eigenvalues and noisedominated images. By using only the coherent parts, the noise is separated from the data, thus improving the results of the spectral processing. The inverse of MNF is generally used to return to the first state of the image (with correct digital numbers "DN") but with less noise. This image can be correctly used for other spectral treatments (classifications or spectral analysis).

2.3.3. Endmembers extraction. The critical step for the classifications in our study is the determination of the endmembers (Training Samples). Their mean statistics and spectra are used as a reference in the algorithm of the classifiers. In the literature, for classifying hyperspectral or multispectral data multiple endmembers extraction methods are cited (Xu et al., 2015; Roth et al., 2012; Veganzones and Graña, 2008)

We opted for a visual technique based on:(i) outcrops in the field (GPS coordinates in support), (ii) visual interpretation on the enhanced images supported by spectral profile of pixels in the best OIF image, and (iii) a vector layer of lithological facies from the geological map at $1 / 50,000^{\circ}$ (Mosaic of sheets mentioned above) recently published (ALVARO et al., 2014a, 2014b; BENHARREF et al., 2014a, 2014c, 2014b). The spectra of the endmembers extracted are presented below (fig. 7).

On the other hand, to limit the spectral similarity between endmembers, we have used the separability of the ROI's pairs to select only the most spectrally distinct ones. After (Csendes and Mucsi, 2016) separability is an accurate method for checking the similarity of a selection of ROI's. In Exelis Envi, the separability is computed with Jeffries-Matusita(JM) distance and Transformed Divergence (Richards and Jia, 2006). In bothmethods, the separability is calculated from class means and covariance matrices. They give indexes values on a scale of " 0 " to " 2 " where " 0 " refers to complete similarity and " 2 " indicate perfect separability.

In our study, and after several attempts to collect the ROI's covering the same facies on all the improved images (DS, PCA and MNF), we opted for a separability threshold of 1.96 for the ROI pairs to be acceptable. The figure7 shows the spectra of the forty two " 42 " endmembers of the area.

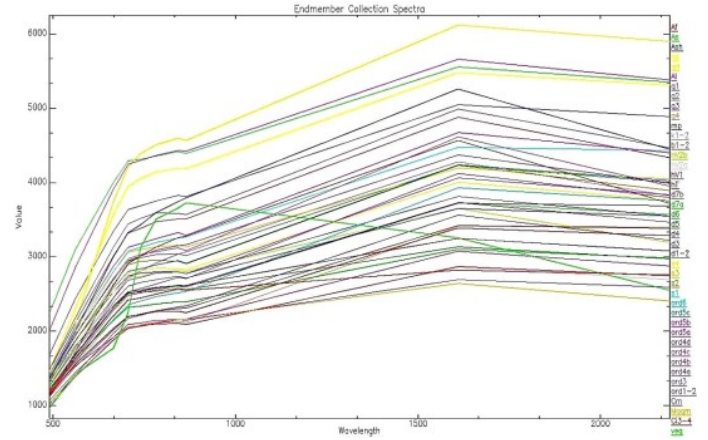

Figure 7: Spectra of endmembers used for lithological classification in the study area

2.3.4. Classification: In order to evaluate the contribution of sentinel-2A images in the litho-facies mapping of the region, we used the supervised classification based on the endmembers that we extracted earlier. The input image was the result of the inverse of MNF, thus with all the spectral characteristics and with very little noise (high $\mathrm{S} / \mathrm{N}$ ratio). Summary of the types of classifications used here is given below.

2.3.4.1. Spectral Angle Mapper: The Spectral Angle Mapper (SAM) is an automated method for comparing image spectra to a reference spectra or a spectral library(Petropoulos et al., 2010). The algorithm determines the similarity between two spectra by calculating the "spectral angle" between them, treating them as vectors in a space with dimensionality equal to the number of bands (nb). SAM determines the similarity of an unknown spectrum t to a reference spectrum $r$, by applying the following equation (CSES, 1992):

$\alpha=\cos ^{-1}\left(\frac{\sum_{i=1}^{n b} t_{i} r_{i}}{\sqrt{\sum_{i=1}^{n b} t_{i}^{2}} \sqrt{\sum_{i=1}^{n b} r_{i}^{2}}}\right)$

Here, $\mathbf{n b}$ : the number of bands in the image, t: pixel spectrum, $\mathbf{r}$ : reference spectrum $\alpha$ : spectral angle

The SAM algorithm implemented in ENVI takes as input a number of "training classes" or reference spectra from ASCII files, ROIs, or spectral libraries. The result is a classification image showing the best SAM match at each pixel. Lighter pixels in the rule images represent smaller spectral angles, and more similarity to the reference spectrum.

2.3.4.2. Maximum likelihood classifier (MLC) is a common multivariate statistical classification method embedded in many image processing software packages.

The MLC calculates the probability that a pixel in the image belongs to a specific class assuming that the statistics of all classes are normally distributed for all bands in the image (Richards, 2013) .

\section{RESULTS}

\subsection{Enhancement images:}

To increase the discrimination of lithological facies in the study area, the decorrelation stretch was applied on the RGB combination with highest OIF. Figure (8) shows this last image in (a). The image resulted from the decorrelation stretch is in (b).

In the image with high OIF, vegetation is in red, the quaternary cover is in white and grey, the sands are in yellow; the Mesozoic and Cenozoic cover are in yellowish green and the Palaeozoic is in dark blue, green and maroon.

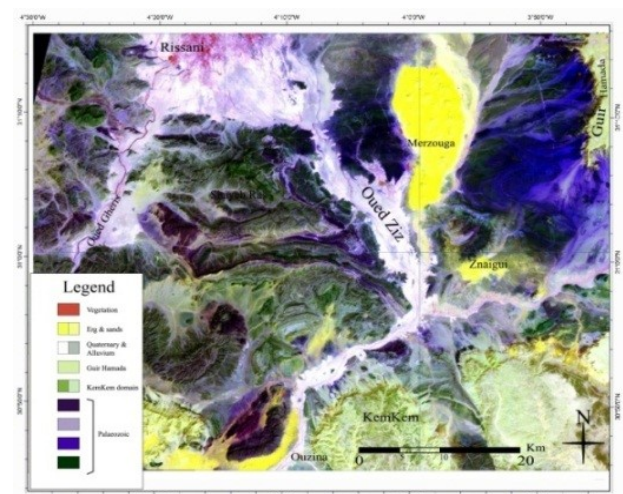

Figure 8: (a) False colour combination with highest OIF $(\mathrm{R}=\mathrm{b} 8, \mathrm{G}=\mathrm{b} 11, \mathrm{~B}=\mathrm{b} 2)$

After the decorrelation stretch and despite the great complexity of the outcrops of the area, the facies could be very well 
distinguished to the human eye. So, we can easily identify the vegetation in neon blue, the sands in green and soft green, the quaternary in purplish grey and dark blue, the Meso-Cenozoic cover in lime green and leaf green and the Palaeozoic formations in the other colours remaining in the image (sky blue, lavender blue, peach, orange, purple, magenta etc ...)

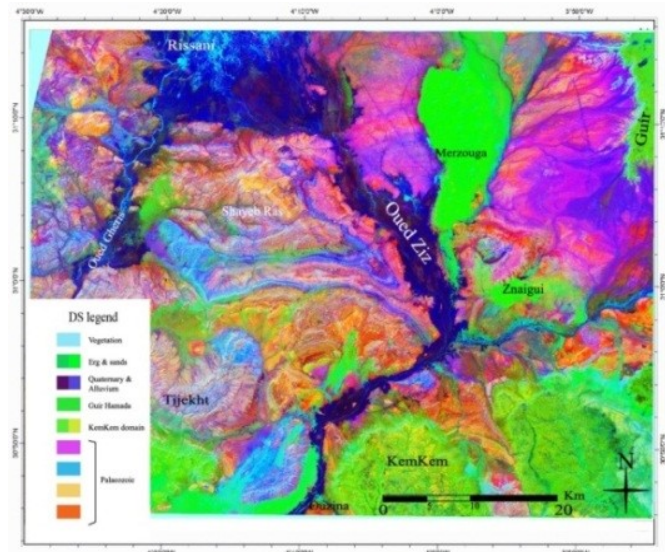

Figure 8: (b) Decorrelation stretch for the best OIF combination $(\mathrm{R}=\mathrm{b} 8, \mathrm{G}=\mathrm{b} 11, \mathrm{~B}=\mathrm{b} 2)$.

\subsection{MNF transformation.}

The transformation of the MNF allowed us to discriminate outcrops still confused at this stage. A very representative example is the relatively thin formations of the first Bani of the Ordovician (ord4a and ord4b). They were well distinguished after this transformation by MNF (fig.10).

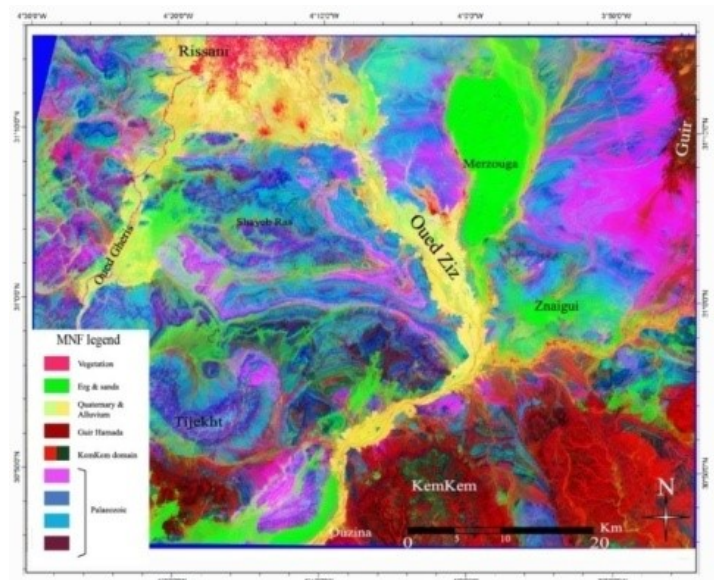

Figure 9: MNF RGB image, with $($ Red=EV1, Green=EV2, Blue $=\mathrm{EV} 3)$

\subsection{Classifications.}

3.3.1. Spectral angle Mapper classification (SAM): Due to the high lithological diversity at the pixel resolution $(10 \mathrm{~m})$, this type of classification based on spectra of outcrops, was not very satisfactory. The figure 10 shows the image resulted.

3.3.2. Maximum likelihood classifier classifications MLC: At first sight, in this classification based on the machine learning, the image resulted (fig.11) was very satisfactory and the outcrops were easier discriminated.

\subsubsection{Accuracy assessment and validation}

3.3.3.1. Accuracy assessment: In order to estimate the percentage of correctly classified pixels, the evaluation of the accuracy of the classification was done by matrix confusion and based on truth points in the field (outcrops with several GPS points).

Testing ROIs collected on a vector layer from the mosaicked geological map at $1 / 50.000^{\circ}$ (figure4) were also used. The figure 12 present the compared overall accuracies and the kappa coefficients for the resulted classifications.

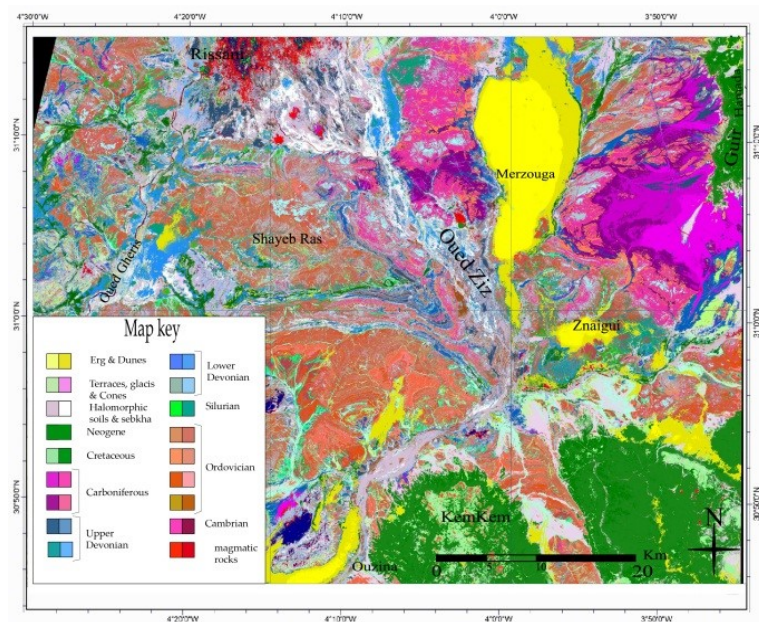

Figure 10: Spectral Angle Mapper classification image

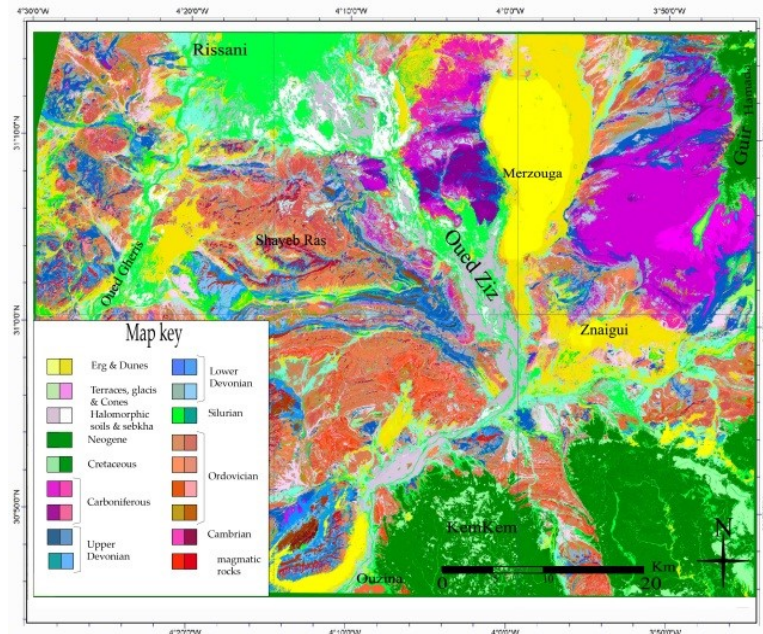

Figure 11: Maximum likelihood classification image

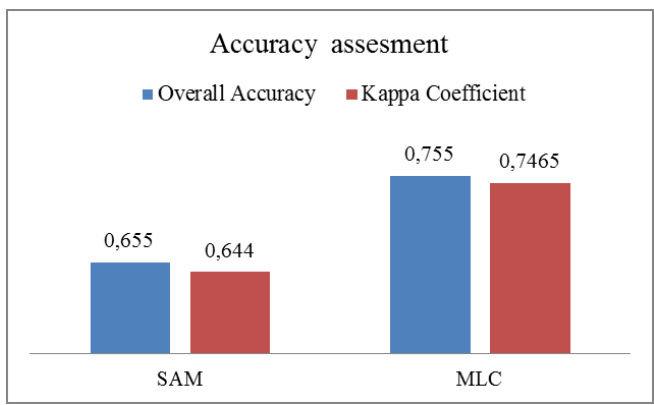

Figure 12: Compared accuracy of SAM and MLC used 3.3.3.2: Validation: The validation was done by identifying classes of the MLC result with their respective landcover (samples from field fig.13) with GPS points support, geologic map at $1 / 50000^{\circ}$ (mosaic of figure4) and Google Earth 
image. The figure15 show some samples and their respective localisation in the map.
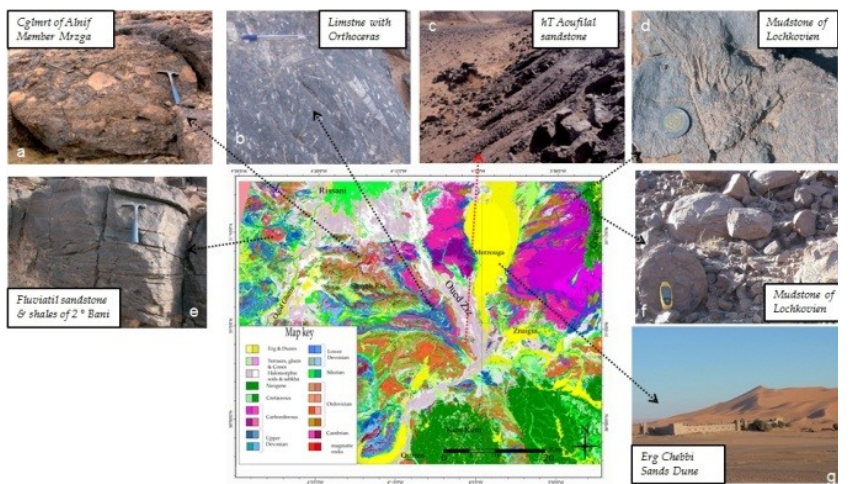

Figure13: samples used for validation with the ANN image

\section{DISCUSSION}

\subsection{Image enhancement:}

In order to have a qualitative evaluation of the contribution of sentinel2A images in lithofacies mapping in our area, a subset of the RUV and RVV granules acquired on the same date (2017-09-13T10: 50: 21) was used in this study. The atmospheric correction was made using the SEN2COR extension integrated into ESA SNAP software.

The great diversity of minerals at the pixel scale has been a major handicap for spectral analysis, usually used in remote sensing studies applied to geology (with spectral libraries ASTER or USGS). However, enhancement treatments of these images using techniques already used on ASTER data (Pour and Hashim, 2012; Rajendran and Nasir, 2017) or LANDSAT (van der Werff and van der Meer, 2016) have yielded very satisfactory results.

First, a resampling of the $20 \mathrm{~m}$ bands $(5,6,7,8 \mathrm{a}, 11$ and 12$)$ to the $10 \mathrm{~m}$ resolution was performed to maximize the accuracy of facies boundaries and minimize confusion between them. The RGB image with the highest value of the OIF (fig. 8a) made it possible to better distinguish the outcrops of the zone. This same RGB combination served as input for the decorrelation stretch process (fig. $8 \mathrm{~b}$ ). The resulting image of this technique showed accurately the Meso-Cenozoic and Quaternary cover formations.

The transformation by MNF made it possible to better discriminate the formations of the substratum which were more confused until this stage. The boundaries between these formations become sharper by using the interactive stretching or by varying the order of channels of this MNF image.

\subsection{Endmembers extraction:}

The extraction of endmembers used as training samples is a decisive step influencing the accuracy of the classification. In this study, we have tried to use the Pixel Purity Index (PPI) method which is widely used and because of its implementation in the Envi software. But, in our case, the spatial heterogeneity of the outcrops and their impurity on the pixel scale has limited the reliability of this method (PPI). Thus, we have used the classical method based on images visual interpretation (DS and MNF), extreme class from scatter plots between the least correlated bands (B11; B8; B2), and pixel spectral plots comparison. Finally, the

\subsection{Classification:}

Two types of classifications were chosen in this study in order to have the most precision for the adoption in lithofacies mapping. These were: (i) SAM based on the average spectral signal of the ROI's and (ii) MLC, learning machine, based on the maximum statistical likelihood between the chosen ROI's. The results obtained showed that the MLC has the highest overall accuracy of $76 \%$ with a Kappa coefficient of 0.75 .

The superposition of this classification image with the geological map shows a great similarity between the classes and the geological formations of the map.

The validation of this classification was based on the samples collected in the field with their GPS coordinates (fig.12), as well as on the recently published geological map.

This study allowed us to classify lithofacies from an arid to semi-arid zone using sentinel $2 \mathrm{~A}$ images. It showed as for (van der Werff and van der Meer, 2016) that sentinel2A images lend themselves very well to geological studies by remote sensing like their predecessors ASTER and LANDSAT.

Finally, by providing in situ measurements of spectral characteristics for typical formations of the region, Sentinel 2 images may allow greater precision in the classification of lithofacies. Thus, it will be a great contribution to the study oriented spectral analysis.

\section{Conclusion}

This paper has highlighted the important role of sentinel2 remotely sensed images in litho-facies mapping of an arid to demi arid region (Tafilalet, Morocco). The enhancements techniques used (OIF, DS, MNF) have permitted discrimination of about all outcrops in the study area with high details (10m of resolution). A comparative classification based on MLC and SAM was developed and has shown that the MLC has given the high accurate results. The overall accuracy based on the confusion matrix was $76 \%$ and the kappa coefficient was 0.75 . The validation of the classification was done with the georeferenced samples from the field (GPS coordinates) and the mosaicked geological map recently published.

So, to act in building the lithological map of our area of study we have opt to use the sentinel-2 images in synergy with enhancements processes (MNF and DS) and maximum likelihood classifier.

Finally, we can conclude that the VNIR and SWIR bands of sentinel2 images with their high spectral and spatial resolutions $(10 \mathrm{~m} \& 20 \mathrm{~m}$ and 12 bands between $443 \mathrm{~nm}$ and $2190 \mathrm{~nm}$ ) can give a very good opportunity for geologists to improve their investigations in the zones with difficult access. Indeed, with a good improvement of these images by the multiple processes currently available and a suitable classification (MLC for our case) we can easily draw up a very accurate litho-facies map.

\section{References}

Abdelmalik, K.W., Abd-Allah, A.M.A., 2017. Integration of remote sensing technique and field data in geologic mapping of an ophiolitic suture zone in western Arabian Shield. J. Afr. Earth Sci. https://doi.org/10.1016/j.jafrearsci.2017.10.006 
Adiri, Z., El Harti, A., Jellouli, A., Lhissou, R., Maacha, L. Azmi, M., Zouhair, M., Bachaoui, E.M., 2017. Comparison of Landsat-8, ASTER and Sentinel 1 satellite remote sensing data in automatic lineaments extraction: A case study of Sidi FlahBouskour inlier, Moroccan Anti Atlas. Adv. Space Res. 60, 2355-2367. https://doi.org/10.1016/j.asr.2017.09.006

ALVARO, J.J., ARETZ M., BENHARREF, M., HIBTI, M., POUCLET, A., EL HADI, H., KAOUKAYA, A., ETTACHFINI, E.M., BOUDAD, L., 2014a. Carte géologique du Maroc au 1/50 000, feuille Taouz, Mémoire explicative.

ALVARO, J.J., BENHARREF, M., HIBTI, M., BOUDAD, L., 2014b. Carte géologique du Maroc au 1/50 000, feuille Irara, Mémoire explicative.

Amri, K., Rabai, G., Benbakhti, I.M., Khennouche, M.N., 2017. Mapping geology in Djelfa District (Saharan Atlas, Algeria), using Landsat 7 ETM+ data: an alternative method to discern lithology and structural elements. Arab. J. Geosci. 10 https://doi.org/10.1007/s12517-017-2883-6

Asadzadeh, S., de Souza Filho, C.R., 2016. A review on spectral processing methods for geological remote sensing. Int. J. Appl. Earth Obs. Geoinformation 47, 69-90. https://doi.org/10.1016/j.jag.2015.12.004

Baidder, L., Michard, A., Soulaimani, A., Fekkak, A., Eddebbi, A., Rjimati, E.-C., Raddi, Y., 2016. Fold interference pattern in thick-skinned tectonics; a case study from the external Variscan belt of Eastern Anti-Atlas, Morocco. J. Afr. Earth Sci. 119, 204-225. https://doi.org/10.1016/j.jafrearsci.2016.04.003

Baidder, L., Raddi, Y., Tahiri, M., Michard, A., 2008. Devonian extension of the Pan-African crust north of the West African craton, and its bearing on the Variscan foreland deformation: evidence from eastern Anti-Atlas (Morocco). Geol. Soc. Lond. Spec. Publ. 297, 453-465. https://doi.org/10.1144/SP297.21

Bannari, A., El-Battay, A., Bannari, R., Rhinane, H., 2018. Sentinel-MSI VNIR and SWIR Bands Sensitivity Analysis for Soil Salinity Discrimination in an Arid Landscape. Remote Sens. 10, 855 https://doi.org/10.3390/rs10060855

Bannari, A., El-Battay, A., Saquaque, A., Miri, A., 2016. PALSAR-FBS L-HH Mode and Landsat-TM Data Fusion for Geological Mapping. Adv. Remote Sens. 05, 246-268. https://doi.org/10.4236/ars.2016.54020

Bannari, A., Girouard, G., Saquaque, A., 2015. Validation of LMSA and SAM for geological mapping: Comparative study among BGIS-2000, TM and ASTER, in: Chan, K. (Ed.), Environmental Engineering and Computer Application. CRC Press, pp. 173-178. https://doi.org/10.1201/b18565-36

BENHARREF, M., ALVARO, J.J., HIBTI, M., POUCLET, A., EL HADI, H., BOUDAD, L., 2014a. Carte géologique du Maroc au 1/50 000, feuille Merzouga, Mémoire explicative.

BENHARREF, M., ALVARO, J.J., HIBTI, M., POUCLET, A., EL HADI, H., KAOUKAYA, A., ETTACHFINI, E.M., 2014b. Carte géologique du Maroc au 1/50 000, feuille Al Atrous, Mémoire explicative.
BENHARREF, M., HIBTI, M., POUCLET, A., EL HADI, H., KAOUKAYA, A., 2014c. Carte géologique du Maroc au 1/50 000, feuille Mfis, Mémoire explicative.

Binam Mandeng, E.P., Bondjè Bidjeck, L.M., Takodjou Wambo, J.D., Taku, A., Bineli Betsi, T., Solange Ipan, A., Tchami Nfada, L., Bitom Dieudonné, L., 2018. Lithologic and structural mapping of the Abiete-Toko gold district in southern Cameroon, using Landsat 7 ETM+/SRTM. Comptes Rendus Geosci. 350, 130-140. https://doi.org/10.1016/j.crte.2017.11.003

Bishop, C., Rivard, B., de Souza Filho, C., van der Meer, F., 2018a. Geological remote sensing. Int. J. Appl Earth Obs. Geoinformation 64, 267-274. https://doi.org/10.1016/j.jag.2017.08.005

Bishop, C., Rivard, B., de Souza Filho, C., van der Meer, F., 2018b. Geological remote sensing. Int. J. Appl. Earth Obs. Geoinformation 64, 267-274. https://doi.org/10.1016/j.jag.2017.08.005

Chavez, P., Berlin, G.L., Sowers, L.B., 1982. Statistical method for selecting landsat MSS. J Appl Photogr Eng 8, 23-30.

Csendes, B., Mucsi, L., 2016. Identification and Spectral Evaluation of Agricultural Crops on Hyperspectral Airborne Data. J. Environ. Geogr. 9. https://doi.org/10.1515/jengeo-2016-0012

Fagbohun, B.J., Adeoti, B., Aladejana, O.O., 2017. Lithostructural analysis of eastern part of Ilesha schist belt, Southwestern Nigeria. J. Afr. Earth Sci. 133, 123-137. https://doi.org/10.1016/j.jafrearsci.2017.05.017

Frampton, W.J., Dash, J., Watmough, G., Milton, E.J., 2013. Evaluating the capabilities of Sentinel-2 for quantitative estimation of biophysical variables in vegetation. ISPRS J. Photogramm. Remote Sens. $82,83-92$ https://doi.org/10.1016/j.isprsjprs.2013.04.007

GREEN, A.A., BERMAN, M., SWITZER, P., 1988. A Transformation for Ordering Multispectral Data in Terms of Image Quality with Implications for Noise Removal. IEEE Trans. Geosci. REMOTE Sens. 26, 10.

Gregory, A.F., 1979. Remote sensing in the search for metallic ores: a review of current practice and future potential (No. 31). https://doi.org/10.4095/106063

Hedley, J., Roelfsema, C., Chollett, I., Harborne, A., Heron, S., Weeks, S., Skirving, W., Strong, A., Eakin, C., Christensen, T., Ticzon, V., Bejarano, S., Mumby, P., 2016. Remote Sensing of Coral Reefs for Monitoring and Management: A Review. Remote Sens. 8, 118. https://doi.org/10.3390/rs8020118

Kaplan, G., Avdan, U., 2017. Object-based water body extraction model using Sentinel-2 satellite imagery. Eur. J. Remote Sens. 50, 137-143. https://doi.org/10.1080/22797254.2017.1297540

Kumar, C., Shetty, A., Raval, S., Sharma, R., Ray, P.K.C., 2015. Lithological Discrimination and Mapping using ASTER SWIR Data in the Udaipur area of Rajasthan, India. Procedia Earth Planet. Sci. 11, 180-188. https://doi.org/10.1016/j.proeps.2015.06.022

Lubeseder, S., Rath, J., Rücklin, M., Messbacher, R., 2010. Controls on Devonian hemi-pelagic limestone deposition analyzed on cephalopod ridge to slope sections, Eastern Anti-Atlas, Morocco. Facies 56, 
295-315. https://doi.org/10.1007/s10347-0090205-5

Michard, A., Hoepffner, C., Soulaimani, A., Baidder, L., 2008. The Variscan Belt, in: Michard, André, Saddiqi, O., Chalouan, A., Lamotte, D.F. de (Eds.), Continental Evolution: The Geology of Morocco: Structure, Stratigraphy, and Tectonics of the Africa-Atlantic-Mediterranean Triple Junction. Springer Berlin Heidelberg, Berlin, Heidelberg, pp. 65-132. https://doi.org/10.1007/978-3-540-7707633

Ninomiya, Y., Fu, B., 2016. Regional Lithological Mapping Using ASTER-TIR Data: Case Study for the Tibetan Plateau and the Surrounding Area. Geosciences 6, 39. https://doi.org/10.3390/geosciences6030039

Petropoulos, G.P., Vadrevu, K.P., Xanthopoulos, G., Karantounias, G., Scholze, M., 2010. A Comparison of Spectral Angle Mapper and Artificial Neural Network Classifiers Combined with Landsat TM Imagery Analysis for Obtaining Burnt Area Mapping. Sensors 10, 1967-1985. https://doi.org/10.3390/s100301967

Pouclet, A., El Hadi, H., Bardintzeff, J.-M., Benharref, M., Fekkak, A., 2017. Devonian to Early Carboniferous magmatic alkaline activity in the Tafilalt Province, Eastearn Morocco: An Eovariscan episode in the Gondwana margin, north of the West African Craton. J. Afr. Earth Sci. 129, 814-841. https://doi.org/10.1016/j.jafrearsci.2017.01.030

Pour, A.B., Hashim, M., 2012. The application of ASTER remote sensing data to porphyry copper and epithermal gold deposits. Ore Geol. Rev. 44, 1-9. https://doi.org/10.1016/j.oregeorev.2011.09.009

Qiu, S., He, B., Yin, C., Liao, Z., 2017. ASSESSMENTS OF SENTINEL-2 VEGETATION RED-EDGE SPECTRAL BANDS FOR IMPROVING LAND COVER CLASSIFICATION. ISPRS - Int. Arch. Photogramm. Remote Sens. Spat. Inf. Sci. XLII2/W7, 871-874. https://doi.org/10.5194/isprsarchives-XLII-2-W7-871-2017

Rajendran, S., Nasir, S., 2017. Characterization of ASTER spectral bands for mapping of alteration zones of volcanogenic massive sulphide deposits. Ore Geol. Rev. 88, 317-335. https://doi.org/10.1016/j.oregeorev.2017.04.016

Richards, J.A., 2013. Remote Sensing Digital Image Analysis. Springer Berlin Heidelberg, Berlin, Heidelberg. https://doi.org/10.1007/978-3-64230062-2

Richards, J.A., Jia, X., 2006. Remote sensing digital image analysis: an introduction, 4 th ed. ed. Springer, Berlin.

Roth, K.L., Dennison, P.E., Roberts, D.A., 2012. Comparing endmember selection techniques for accurate mapping of plant species and land cover using imaging spectrometer data. Remote Sens. Environ. 127, 139-152. https://doi.org/10.1016/j.rse.2012.08.030

Satellite Missions Directory - Earth Observation Missions eoPortal [WWW Document], n.d. URL https://directory.eoportal.org/web/eoportal/satellitemissions/ (accessed 6.11.18).

SEN2COR, n.d.

Soulaimani, A., Burkhard, M., 2008. The Anti-Atlas chain (Morocco): the southern margin of the Variscan belt along the edge of the West African craton.
Geol. Soc. Lond. Spec. Publ. 297, 433-452. https://doi.org/10.1144/SP297.20

Toming, K., Kutser, T., Laas, A., Sepp, M., Paavel, B., Nõges, T., 2016. First Experiences in Mapping Lake Water Quality Parameters with Sentinel-2 MSI Imagery. Remote Sens. 8, 640 . https://doi.org/10.3390/rs8080640

van der Meer, F.D., van der Werff, H.M.A., van Ruitenbeek, F.J.A., 2014. Potential of ESA's Sentinel-2 for geological applications. Remote Sens. Environ. $148,124-133$. https://doi.org/10.1016/j.rse.2014.03.022

van der Meer, F.D., van der Werff, H.M.A., van Ruitenbeek, F.J.A., Hecker, C.A., Bakker, W.H., Noomen, M.F., van der Meijde, M., Carranza, E.J.M., Smeth, J.B. de, Woldai, T., 2012. Multi- and hyperspectral geologic remote sensing: A review. Int. J. Appl. Earth Obs. Geoinformation 14, 112-128. https://doi.org/10.1016/j.jag.2011.08.002

van der Werff, H., van der Meer, F., 2016. Sentinel-2A MSI and Landsat 8 OLI Provide Data Continuity for Geological Remote Sensing. Remote Sens. 8, 883. https://doi.org/10.3390/rs8110883

Veganzones, M.A., Graña, M., 2008. Endmember Extraction Methods: A Short Review, in: Lovrek, I., Howlett, R.J., Jain, L.C. (Eds.), Knowledge-Based Intelligent Information and Engineering Systems. Springer Berlin Heidelberg, Berlin, Heidelberg, pp. 400-407. https://doi.org/10.1007/978-3-540-85567550

Xu, Y., Shi, J., Du, J., 2015. An Improved Endmember Selection Method Based on Vector Length for MODIS Reflectance Channels. Remote Sens. 7, 6280-6295. https://doi.org/10.3390/rs70506280 